\title{
ПИРИНГОВАЯ ПРАВОВАЯ ПАРАДИГМА КАК В0ЗМОЖНОЕ НАПРАВЛЕНИЕ ТРАНСФОРМАЦИИ ЗАКОНОДАТЕЛЬНОГО РЕГУЛИРОВАНИЯ ВИРТУАЛЬНОГО ДЕЦЕНТРАЛИЗОВАННОГО ПРОСТРАНСТВА
}

\begin{abstract}
PEER-TO-PEER LEGAL PARADIGM
AS A POSSIBLE DIRECTION
OF THE LEGISLATIVE REGULATION
TRANSFORMATION OF THE VIRTUAL
DECENTRALIZED SPACE
A. Lomakin

S. Rudikova

Summary. Nowadays, socio-economic relations in society are rapidly transforming under the influence of its digital development. In turn, the development of online processes causes the emergence of new financial threats. Consequently, such situation should be accompanied by appropriate changes in the law. However, traditional law is clearly undergoing a crisis, being unable to adapt to the new online system quickly. In this article the authors propose a fundamentally new approach to understanding the modern law, which is called "peer-to-peer legal paradigm". The authors determine the basics of the new concept, reveal its main principles and explain the need for its application in modern realities. There are new interpretations of well-known terms such as a legal provision and a normative legal act in the peer-to-peer legal paradigm. Such interpretations emphasize the refusal from the traditional legal system through the use of the IT sphere modern terminology. The article also reveals the functioning processes of peer-to-peer networks, identifies and describes the characteristic features of a decentralized peer-to-peer system. The authors find out the idea of using Big Data technology and smart contracts in a new paradigm and highlight the advantages and disadvantages of the new concept. The presented view of the transformation of the traditional legal system is the key decision to eliminating and minimizing the probability of financial threats (especially Internet fraud). Due to the transformation of law in the digital period, both economists and lawyers will be interested in this peer-to-peer legal paradigm.
\end{abstract}

Keywords: peer-to-peer networks, legal paradigm, digitalization, decentralized peer-to-peer systems, financial threats.

\author{
Ломакин Андрей Леонидович \\ Д.э.н., профессор, Российская академия народного \\ хозяйства и государственной службы при Президенте \\ $P Ф(P A H X U \Gamma C)$ \\ lomakin-al@ranepa.ru \\ Рудикова Софья Сергеевна \\ Российская академия народного хозяйства \\ и государственной службы при Президенте РФ (РАНХИГС) \\ rudikovasofia@gmail.com
}

Аннотация. В настоящее время социально-экономические отношения в обществе стремительно преобразуются под влиянием его цифровой эволюции. В свою очередь развитие онлайн-процессов порождает возникновение новых финансовых угр0з, поэтому такая ситуация должна сопровождаться соответствующими изменениями в законодательстве. Однако традиционное право явно претерпевает кризис, будучи не в состоянии быстро подстроиться под новую онлайн-систему. В данной статье авторами предлагается принципиально новый подход к пониманию современного права, который получил название «пиринговая правовая парадигма». Авторы детерминируют основы новой концепции, раскрываю её базовые принципы и объясняют необходимость её применения в современных реалиях. В рамках пиринговой правовой парадигмы предлагаются новые трактовки таких общеизвестных терминов, как правовая норма и нормативно-правовой акт, в которых подчеркивается уход от традиционной системы права благодаря использованию современной терминологии IT-сферы. В статье также раскрываются процессы функционирования пиринговых сетей, выделяются и описываются характерные особенности децентрализованной пиринговой системы. Авторами раскрыта идея использования технологии Больших данных и смарт-контрактов в новом контексте, а также выделены преимущества и недостатки новой парадигмы. Представленный взгляд на трансформацию традиционной правовой системы является ключом к устранению и минимизации вероятности реализации финансовых угр0з, в особенности мошенничества в Интернете. Ввиду того, что затронуты актуальные процессы трансформации права в эпоху цифровизации, такой взгляд будет интересен специалистам как в области экономики, так и в области юриспруденции.

Ключевые слова: пиринговые сети, правовая парадигма, цифровизация, децентрализованные пиринговые системы, финансовые угрозы. 


\section{Ввемение}

$\Pi$ иринг (от англ. peer-to-peer, или Р2P) - это взаимовыгодный обмен данными между двумя и более пользователями сети, основанное на принципе взаимного использования ресурсов (дискового пространства и информации в любых ее формах). Так как пиринговая система представляет собой распределенную базу данных, она позволяет пользователям получать доступ к открытой информации друг друга [4, с. 24].

Парбануэлл Йохнухуйтсман впервые использовал словосочетание «peer to peer» при разработке сетевой архитектуры Advanced Peer to Peer Networking для фирмы IBM в 1984 году. Так и возникло само название технологии Р2Р. В настоящее время системы Р2Р успешно используются для проведения сложных расчетов и оказания различного рода услуг (например, интернет-телефония) [4, с. 24].

Децентрализованные, или одноранговые пиринговые системы являются одним из видов таких систем: их характеризует полное отсутствие централизующего звена - выделенного сервера, поскольку каждый узел (peer) одновременно является и клиентом, и сервером. Главным преимуществом децентрализованной системы является надежность, которая обеспечивается отсутствием сервера, генерирующего информацию о пользователях [4].

В связи с активным развитием современных технологий и трансформацией экономики в цифровую, многие социально-экономические процессы (инвестирование, торговля, страхование, образование в Интернете и т.п.) начали активно развиваться и стали децентрализованными, а значит, требующими нового подхода к их законодательному регулированию. Однако, все чаще происходит так, что возникновение и функционирование подобных явлений намного опережают их правовое регулирование или вовсе контроль таких явлений невозможен, так как государство не в состоянии усовершенствовать традиционное право таким образом, чтобы децентрализация функционировала эффективно и в рамках правового поля.

Сложившиеся обстоятельства заставляют искать иные, более современные пути разрешения данной проблемы, которые должны основываться на передовых достижениях человека.

\section{^итературный обзор}

Научные статьи последних лет посвящены идеям и примерам того, как используются пиринговые сети и как они способны видоизменить традиционную эко- номику. Так, формулируется академическое определение шэринговой экономики и её ключевые принципы функционирования (принципы пиринга, экологичности, саморегулирования, рациональности, открытости)[5], даётся описание принципа работы пиринговой системы [2] и даже рассматривается влияние пиринговых сетей на развитие телекоммуникаций и изменения в сфере образования [2].

Вопросы законодательного регулирования различных сфер, функционирующих на базе таких сетей также поднимаются в ряде работ. Например, американский ученый J.M. Walter затрагивает вопросы нарушения авторских прав в цифровую эпоху и невозможности традиционным способом эффективно контролировать этот процесс. Основным выводом является то, что попытка закрыть доступ к файлам нелегальных источников (или посредников) пиратских товаров по-прежнему остается сложной задачей для регулирования [6].

Однако имеющиеся работы вовсе не рассматривают пиринговую сеть как основу для формирования новой системы взглядов на существующее право, поэтому предлагаемая пиринговая правовая концепция является принципиально новым подходом к пониманию современного права. Данная статья подробно раскрывает идею парадигмы, впервые выдвинутую авторами в своей работе, посвященной анализу функционирования хайп-проектов в Интернете [3].

\section{Сомержание исслеАования}

Пиринговая правовая парадигма (далее - ППП) представляет собой принципиально новую систему права, построенную на функциональных закономерностях.

Пиринговая правовая парадигма - это концепция свода правил (алгоритмов) о создании пространства нового права, выработанных для регулирования децентрализованных процессов в общество вследствие его цифровой трансформации.

Идея новой парадигмы состоит в создании концепции свода правил, или свода алгоритмов - одноранговой системы в пространстве нового права, которая будет реализовываться через новые информационные и облачные технологии [3, с. 44].

В рамках ППП привычным для нас понятиям «правовая норма» и «нормативно-правовой акт» присваивается иное значение. Так, в контексте новой концепции данные термины приобретают новый смысл и будут трактоваться следующим образом. 
Правовая норма - элементарное общеобязательное правило поведения в Интернет-пространстве, выраженное в форме цифрового кода.

Нормативно-правовой акт (цифровой акт, или нормативно-цифровой акт) - строго определенный набор кодов, содержащий в себе общеобязательные правила поведения внедренный в цифровое пространство с целью регулирования Интернет-отношений в обществе.

При этом, привычная форма систематизации нормативно-правовых актов исчезает. ППП представляет собой цифровые алгоритмы и программные коды, предполагающие исключительно прямой характер действия в установленных границах, поэтому необходимость в изучении правовых норм (в традиционном их понимании) утрачивается.

Помимо базовых дефиниций для более полного понимания ППП необходимо рассмотреть и принципы, на которых она основывается:

1. Непрерывность процесса регулирования.

2. Превентивный характер действия.

Интерес и угроза сосуществуют на основе закона единства и борьбы противоположностей: устранение угрозы возможно только посредством устранения интереса, поэтому самым эффективным способом воздействия на угрозу является управление интересом. Необходимо так сформулировать норму права, чтобы менеджмент интересов не позволял угрозе реализоваться. Такой подход ведет к принципиальной невозможности совершения какого-либо действия в обход существующих норм права.

3. Безальтернативность.

Данный принцип обеспечивается посредством перехода от «стохастической» модели традиционного права к функциональной зависимости, то есть появляется однозначное соответствие факторного и результирующего признаков.

Первые три принципа имеют фундаментальный характер, так как только при условии их выполнения остальные принципы будут иметь смысл в процессе реализации рассматриваемой концепции.

4. «Растворение» права в Интернет-пространстве.

5. Наднациональный характер. Устраняется географическая ограниченность действия права в Интернет-пространстве.

6. Равенство каждого участника перед системой (равноправие).

7. Отсутствие риска потерять денежные средства как дополнительная, раннее отсутствующая свобода граждан в своих действиях.

8. Справедливость.
9. Общеобязательность.

10. Принудительность (сочетание убеждения и принуждения).

11. Высокая скорость внедрения новой нормы, динамизм, выражающийся в быстрой реакции со стороны права на проблему в обществе.

12. Стабильность и бесперебойность функционирования.

13. Законность.

14. Гласность.

15. Высокая эффективность.

Известно, что любой закон имеет свою географию действия, следовательно регулирование деятельности в Интернете возможно исключительно через интеграцию права в новое пространство - цифровое, где оно, наряду со всеми сетевыми процессами, станет децентрализованным.

Известно, что технология «Больших данных» (Big Data) позволяет анализировать большие пласты информации. Также общеизвестно, что в юриспруденции есть такие понятия, как «буква закона» и «дух закона». Какая же взаимосвязь между этими двумя фактами в новой концепции? Так, в Big Data под «буквой закона» будет пониматься структурированная база данных (т.е. описание протекающих между субъектами процессов), а под «духом закона» будет пониматься неструктурированная база данных (например, информация о продажах, покупках и т.д.). Фундаментом для новой правовой парадигмы станет новая технология блокчейн (blockchain). Если записи в блокчейн-реестре были получены без нарушений, то они могут быть представлены в суде в качестве доказательств. С юридической точки зрения это станет возможным благодаря хэш-коду, которым фиксируется запись в блокчейне: это не что иное, как электронный документ, который может являться письменным доказательством в суде при нарушении законодательства и прав граждан и выявлении мошеннических операций.

В рамках пиринговой правовой парадигмы контакты между субъектами строго регламентируются, а функционирование осуществляется аналогично механизму смарт-контрактов (самоисполняемых соглашений)- способу исполнения обязательств посредством сценария, заложенного в программном коде, и его реализации в системе блокчейн [3, с. 44].

Согласно описанной концепции, контакты изначально будут находиться в регулируемом новой системой права Интернет-пространстве, что сделает проведение незаконных операций сложнореализуемым, практически невозможным на данном этапе развития IT-технологий действием. 
Важно подчеркнуть, что появление новой парадигмы не предполагает отказа от традиционной правовой системы. Когда большая часть контактов между субъектами будет проводиться в виртуальном пространстве, новая концепция станет основой регулирования взаимодействий в обществе, а существующее законодательство - её частным случаем [3, с. 44]. В данный момент времени наблюдается обратная ситуация - идея концепции понимается как частный случай традиционного права и так будет до тех пор, пока общество полноценно не «цифровизуется» под влиянием научно-технического прогресса. Однако, как показывает практика, уже сейчас процессы в обществе развиваются достаточно стремительно, поэтому уже в течение ближайших 20 лет (а то и меньше) мы заметим существенные изменения в праве в пользу предлагаемой концепции.

\section{Результаты}

Данное направление трансформации правовой системы является новым подходом к устранению экономических (в первую очередь финансовых) угроз. Преимуществом новой концепции является иной механизм работы, который предполагает полную интеграцию надзора за исполнением закона в виртуальное пространство с целью регулирования реальной деятельности, а также функционирование системы права на основе принципа превентивности, который сводит возможность нарушения законодательства к нулю. К недостатку можно отнести сложность внедрения и затяжной переходный период, так как долгое время два типа подходов - традиционный и новый - будут сосуществовать вместе.

Всё названное возможно осуществить только с помощью полноценной цифровой трансформации общества, к которой сейчас стремится каждое государство. Обязанность правительств в таком случае (согласно одному из основополагающих правил Хартии глобального информационного пространства) состоит в согласовании своих действий по созданию безопасного киберпространства, безопасности информационных систем, защищенных от преступности, в том числе от транснациональной организованной преступности.

\section{Зак^ючение}

Цифровая трансформация традиционной экономики - неизбежный процесс, с которым параллельно должны происходить изменения и во всех других сферах жизнедеятельности человека. В частности, право должно одним из первых реагировать на новые реалии, изменяться также радикально, как и сами регулируемые им процессы, дабы не допускать роста мошенничества и преступности в виртуальном децентрализованном пространстве ввиду отсутствия должного контроля за данными процессами. Пиринговая правовая парадигма - это система права, отвечающая требованиям цифровизации социально-экономических отношений в современном обществе и способная регулировать процессы, не подвластные традиционному праву.

\section{ЛИТЕРАТУРА}

1. Ж Жмакина М. В. Пиринговое обучение как результат трансформации системы взаимодействий в школе // Современная наука: актуальные проблемы теории и практики. Серия «Гуманитарные науки».—2017. -№ 3. -С. 49-53.

2. Касаева Д.Р., Саханский Ю. В. Пиринговые сети как основное направление развития глобального информационного обмена // Научные исследования и перспективные проекты 2017. Сборник трудов 2-й научно-практической конференции аспирантов, преподавателей, ученых. - 2017. -С. $22-27$.

3. Ломакин А.Л., Рудикова С. С. Хайп-инвестирование в Интернете как угроза финансовой безопасности личности и способы борьбы с ним [Электронный ресурс] // East European Scientific Journal \#2 (42), 2019 part 3. C. 41-45. URL: https://eesa-journal.com/wp-content/uploads/EESA_journal_3_part15.pdf (дата обращения: 03.05.2020).

4. Симоненко В. В. Пределы законного использования систем Р2Р в России // Юрист. - 2010. -№ 2. -С. 24-29.

5. Швед В.В., Омельченко Е. В. Шэринговая экономика как путь развития мировой экономики // Вестник Коми республиканской академии государственной службы и управления. Серия: теория и практика управления.-2017. -№ 18 (23). -С. 117-121.

6. Walter, J. M. Regulating mediators of internet piracy: P2P websites and cyberlockers (2019) Digital Policy, Regulation and Governance, 21 (5), pp. 494-509. D0I: 10.1108/DPRG-05-2019-0035. 